\title{
El sitio y la ocupación de Morelia durante la rebelión delahuertista. Enero de 1924
}

\author{
Luis Sánchez Amaro* \\ UNIVERSIDAD MICHOACANA DE SAN NICOLÁS DE HIDALGO
}

El artículo trata sobre cómo se llevó a cabo el sitio y la ocupación de Morelia durante la rebelión delahuertista en Michoacán, en enero de 1924, y las repercusiones que tuvo en el desarrollo de las estrategias militares tanto del presidente Obregón como del general Enrique Estrada, jefe militar de los rebeldes de occidente. Se analiza también la actuación del general Manuel N. López, el gobernador Sidronio Sánchez Pineda y de los demás defensores de la plaza, así como los principales eventos que ocurrieron enseguida de la ocupación de la capital del estado por las fuerzas rebeldes.

(Adolfo de la Huerta, rebelión delahuertista, Michoacán, Morelia)

\section{INTRODUCCIÓN}

I

a rebelión delahuertista de 1923-1924 fue un acontecimiento de carácter nacional que implicó una confrontación social y dencial de 1924, en la que Álvaro Obregón impuso como candidato oficial al general Plutarco Elías Calles con la pretensión de que éste le apoyara después para reelegirse en la Presidencia de la República, como efectivamente sucedió. Esta rebelión acaudillada formalmente por Adolfo de la Huerta se inserta dentro del periodo de reconstrucción económica y política del Estado mexicano, al término de la Revolución de 1910, y que se le conoce como la etapa del caudillismo revolucionario. En esta coyuntura se enfrentaron diversas fuerzas y

\footnotetext{
*sanchezamaro@hotmail.com
} 
grupos atendiendo a intereses y ambiciones particulares, pero también a proyectos políticos que empujaban cambios y reformas sociales o la conservación de estructuras y privilegios. Del lado del presidente Obregón y del general Plutarco Elías Calles se incorporaron en esta lucha los contingentes obreros representados principalmente por la Confederación Regional Obrero Mexicana (сRом), a los cuales les interesaba la alianza con el obregonismo para imponer al capital el cumplimiento del Artículo 123, que significaba la materialización, por una parte, de las conquistas alcanzadas por la clase obrera por su participación en la Revolución y, por otra, el reconocimiento de la nueva legalidad y del papel arbitral del Estado en el ámbito de las relaciones laborales. También estuvieron en apoyo de Obregón y Calles el movimiento campesino agrarista al que le interesaba la continuidad del reparto agrario, el cual se veía en peligro, si triunfaba el delahuertismo, pues, varios de los principales líderes rebeldes eran connotados antiagraristas como el propio general Enrique Estrada y también el general Guadalupe Sánchez. Era evidente que en el bando del movimiento rebelde delahuertista formaban filas los sectores más conservadores que se oponían a muchos de los cambios progresistas, tanto en lo económico como en lo social, que venía impulsando el régimen obregonista y que los afectaba en alguna medida en sus intereses, éstos eran importantes sectores del clero católico, y terratenientes que se acercaron a los militares descontentos por la disminución de sus privilegios y por la imposición de la candidatura oficial de Calles, a quien consideraban sin méritos militares para ocupar la presidencia, $y$, en alianza, intentaron encontrar en la figura de De la Huerta un respaldo en sus pretensiones convirtiéndolo en el "Jefe Supremo" de su lucha armada para derrocar al gobierno instituido.

La derrota del movimiento rebelde permitió a una fracción de la burguesía que representaba el obregonismo imponer su proyecto de reconstrucción económica y de modelo de Estado centralizado, autoritario, pero sustentado en un pacto social con las masas obreras y campesinas, a las que se debían conceder reformas a cambio de su apoyo para llevar a cabo la modernización económica del país.

El tema de la rebelión delahuertista en Michoacán no ha sido abordado por ningún historiador como objeto principal de estudio. 
Existen trabajos que abordan este tema desde una perspectiva nacional, otros abarcan aspectos relacionados con la coyuntura política o del periodo 1923-1924, unos más tratan temas regionales relacionados con este proceso o el periodo histórico y que nos sirven como antecedentes y nos aportan información sobre algunos eventos o personajes del contexto regional. Se suman además trabajos de investigación, biografías, memorias o testimonios sobre algunos protagonistas y participantes del movimiento delahuertista en los ámbitos nacional, regional o local que permiten un acercamiento al tema para quienes estén interesados.

Entre las obras que abordan el proceso de la rebelión delahuertista desde una perspectiva nacional y con un carácter académico destaca, en primer lugar, la de Enrique Plasencia, Personajes y escenarios de la rebelión delahuertista. Esta obra analiza la rebelión en función de los distintos frentes integrados para suprimir la rebelión, así como las fuerzas que combatieron, destacando sus estrategias militares. En su capítulo II sobre el Frente de Occidente aborda el desarrollo del movimiento en Michoacán y de cuya lectura pudimos ubicar el contexto regional y los vínculos de los rebeldes con los líderes nacionales. Aporta, además, gran número de referencias documentales y una metodología rigurosa, por lo que puede considerarse el mejor estudio académico que se ha hecho sobre este proceso hasta la fecha.

Otra obra académica importante es El levantamiento delahuertista cuatro rebeliones y cuatro jefes militares, de Fidelina G. Llerenas y Jaime Tamayo, en la que con base en un riguroso trabajo de investigación documental y bibliográfica se concluye que dicha rebelión no fue una sino en realidad cuatro, cada una con su propio caudillo militar. Destaca en este trabajo su aporte a la conceptualización de dicha rebelión más allá de una mera asonada militar o levantamiento armado, y su búsqueda por explicar lo que la sustentaba en el fondo, así como sus consecuencias en el proceso de conformación del nuevo Estado mexicano.

Resalta también, Adolfo de la Huerta, la integridad como arma de la revolución, de Pedro Castro. Esta obra es una biografía política de Adolfo de la Huerta que tiene la virtud de rescatar a un personaje desdeñado por la historiografía. En este libro casi no se encuentra 
información sobre la rebelión delahuertista en Michoacán, pero es muy importante su estudio para adentrarse en el conocimiento de uno de los actores principales de esta trama histórica, y para descubrir sus relaciones con los demás protagonistas, principalmente, con los otros miembros del llamado Triángulo Sonorense.

Se cuenta entre las obras testimoniales con la de Luis Monroy Durán, El último caudillo: apuntes para la historia de México, acerca del movimiento armado de 1923, en contra del gobierno constituido, en cuyo contenido se describen los antecedentes y el inicio de la rebelión en la nación y luego se procede a hacer un recuento de lo sucedido en cada uno de los estados donde se llevó a cabo el movimiento. Esta obra se editó en 1924 y tiene un tinte claramente oficialista, a pesar de esto ofrece una visión pormenorizada de los hechos y de los personajes que participaron.

En el mismo tenor que la anterior se encuentra la obra de Alonso Capetillo (delahuertista arrepentido), La rebelión sin cabeza: (génesis y desarrollo del movimiento delahuertista), editada hacia 1925, y en la que el autor ofrece su visión de la insurrección en un riguroso orden cronológico. Este trabajo debe leerse con mucho cuidado, pues, denota mucha pasión y una deliberada intención de desprestigiar al movimiento y a su líder formal, Adolfo de la Huerta.

En cuanto a algunos estudios regionales que abordan temas relacionados con la rebelión delahuertista debemos citar el de Verónica Oikión Solano titulado Los hombres del poder en Michoacán 19241962 en la que en su primer capítulo "Los michoacanos... ¿aptos para el poder del caudillo?", trata de la situación política del estado en la coyuntura de la rebelión delahuertista en Michoacán. En esta parte ubica y caracteriza la situación del gobierno encabezado por Sidronio Sánchez Pineda y los actores principales del escenario político regional en ese momento. Describe con datos precisos cómo se desencadenaron los hechos principales de la rebelión y su desenlace.

El libro testimonial, La última batalla, escrito por el general Nazario Medina Domínguez, quien participó directamente en la defensa de Morelia atacada por los delahuertistas, está redactado en forma de crónica y en él da cuenta de diversos acontecimientos del periodo revolucionario en los que el autor participó o tuvo conoci- 
miento de fuentes directas. El trabajo no está metódicamente estructurado ni contiene referencias documentales. Sin embargo, sus descripciones aportan datos y puntos de vista relevantes para poder complementar o refutar informaciones de otros autores y para construir el bosquejo histórico inicial de lo que fue el principal hecho de armas de la rebelión delahuertista en Michoacán: la toma de Morelia.

José C. Valadés publicó, en 1937, Rafael Buelna las caballerías de la revolución, se trata de un texto de 18 capítulos acerca de la vida y muerte del general Rafael Buelna. La narración de las andanzas de Buelna en la rebelión delahuertista inicia a partir del capítulo 12 y termina en el último con la muerte de dicho general durante la toma de Morelia. Es relevante la biografía por la información de primera mano que maneja y con fuentes documentales de difícil localización. Es de notar que las fechas sobre el ataque a Morelia y la muerte de Buelna que exhibe el autor son erróneas.

El libro Memorias de Simón Cortés Vieyra (1880-1963) aporta información acerca del inicio de la rebelión delahuertista en Michoacán y específicamente sobre la participación de este personaje en el sitio y toma de la ciudad de Morelia, en la cual se refleja una visión de los hechos, desde la perspectiva de un campesino sin mucha formación política, que además nos deja entrever que sus motivaciones para inmiscuirse en la rebelión no fueron particularmente políticas sino de carácter personal y de amistad y de descontento contra el gobierno estatal por el trato recibido. ${ }^{1}$

Esta rebelión delahuertista, aunque no fue la última, sí fue una de las más importantes en tanto que involucró a más de la mitad del ejército federal y a uno de los partidos políticos con mayor representación en el escenario político del país, el Partido Cooperatista Nacional ( $\mathrm{PCN}$ ), así como a varios líderes civiles de experiencia y representatividad entre la clase política oficial. El movimiento rebelde se extendió en Michoacán y aunque el estado no fue escenario de las batallas militares decisivas, es destacable, dentro de este conjunto de hechos, por ser el momento de mayor auge, el sitio y la ocupación de Morelia, pero también del inicio del declive de la rebelión.

\footnotetext{
${ }^{1}$ Véanse, al final en el apartado de la bibliografía, los datos completos de estas obras.
} 
La pregunta central que pretendo responder en este artículo es la siguiente: ¿cómo se desarrolló y qué resonancia tuvo el sitio y ocupación de Morelia por los rebeldes delahuertistas en el contexto de la estrategia militar desarrollada por ambos bandos? Lo anterior a partir de la revisión de fuentes primarias disponibles y accesibles, tanto locales como nacionales, que expongo en el desarrollo de mi escrito.

La estrategia militar y el plan inicial que estableció el presidente Obregón para acabar con la rebelión de Estrada en el occidente pretendía atacar por diferentes frentes. Uno, desde Tepic con dos regimientos traídos desde el río Mayo y apoyados por un batallón; otro era una columna de 2 mil hombres al mando del general Lázaro Cárdenas, quien tenía que adentrarse en el estado de Jalisco, sobre la sierra de Mazamitla y bordear el lago de Chapala, hasta llegar a Zacoalco, para cortarle la retirada al enemigo en la vía que une a Guadalajara con Manzanillo. Desde este puerto también se intentaría un desembarco de tropas traídas por los barcos México y Bolivar y protegidas por el cańonero Progreso. Al mismo tiempo, la columna principal al mando del general Joaquín Amaro atacaría el núcleo principal de las fuerzas estradistas que se encontraban en Ocotlán, avanzaría sobre Guadalajara siguiendo la vía del ferrocarril.

El general Cárdenas fue derrotado, herido y apresado en Huejotitlán, Jalisco, el 26 de diciembre de 1923 por el general Rafael Buelna. El general Estrada luego de este triunfo sobre la columna de Cárdenas, el 7 de enero de 1924, instaló su cuartel general en La Piedad, pero tenía el temor de que en una ofensiva formal de Obregón escasearan las municiones por lo que veía la necesidad de abreviar la campaña. Por otro lado, Estrada abrigaba grandes esperanzas de que si se lograba coordinar un avance conjunto sobre la capital del país con Guadalupe Sánchez desde Veracruz y Puebla, con Rómulo Figueroa desde Guerrero, Obregón tendría que distraer fuerzas y él podría ocupar Morelia y continuar hacia el Estado de México, quizás hasta las goteras de la capital de la República. Obregón, en cambio, creía que le favorecía alejar a Enrique Estrada y el grueso de sus fuerzas de su base en Guadalajara para iniciar el ataque en el frente de Ocotlán, y siguiendo las vías del tren tratar de recuperar la Perla Tapatía. Con esta percepción a Obregón, desde un prin- 
cipio, no le interesaba defender la ciudad de Morelia de un posible ataque delahuertista como lo confirma el testimonio del general Juan Gualberto Amaya que señala lo siguiente:

Es justo reconocer la bravura y hombría con que el general López [defensor de la plaza de Morelia] aceptó tan desigual batalla, sin probabilidades de recibir algún refuerzo, puesto que él sabía perfectamente que los planes del general Obregón eran muy opuestos a la defensa de Morelia, toda vez que al ordenar la retirada rumbo a Yuriria, se trataba precisamente de obligar a Estrada a que se alejara de su base todo lo más posible y fomentar su tentación para ver si alargaba su marcha, intentando interponerse sobre la línea férrea al Sur rumbo a la Capital. ${ }^{2}$

Lo anterior explica porque los defensores de la capital michoacana enfrentaron el asedio de manera desventajosa (diez atacantes por un defensor) y no recibieron ninguna ayuda, quedando limitados a sus propias fuerzas y capacidad.

\section{PRIMERAS DisPoSicioneS DEFENSIVAS \\ Y UN GRAVE ERROR TÁCTICO}

Desde el 10 de marzo de 1922, el estado de Michoacán era gobernado por Sidronio Sánchez Pineda, diputado local de la corriente mugiquista, que había sido nombrado como gobernador sustituto luego de que el general Francisco J. Múgica se había visto obligado a pedir licencia ante las presiones de la oligarquía local y el clero político michoacano, la serie de rebeliones armadas surgidas en contra de su gobierno y la evidente falta de apoyo para combatirlas de parte del gobierno del centro. ${ }^{3}$ Desde su arribo al poder estatal Sán-

\footnotetext{
2 Juan Gualberto Amaya, Los gobiernos de Obregón, Calles y regimenes "peleles" derivados del callismo, México, s.i., 1947, 46.

${ }^{3}$ Según los estudiosos de este periodo fueron varios los factores que llevaron al derrocamiento de Múgica: la gran oposición interna en el estado que despertó con su intención de implementar un radical programa de reformas sociales apegadas al pie de la letra de los artículos 3, 27, 123 y 130, constitucionales; luego, su intransigencia política en la defensa de la soberanía de su gobierno y las diferencias con el gobierno de Obregón en materia agraria y militar; su enfrentamiento directo y personal con el general Enrique
} 
chez Pineda le dio la espalda a su antiguo jefe político Múgica y se plegó totalmente a las directrices del gobierno central manteniéndose como titular del poder ejecutivo con el apoyo del presidente Obregón. Al inicio de la rebelión delahuertista y en cuanto el gobernador del estado, Sidronio Sánchez Pineda, tuvo noticia del referido movimiento subversivo, así fuera extraoficialmente, le dirigió un mensaje de apoyo y lealtad al presidente Obregón, en nombre del pueblo michoacano y del suyo propio, y se puso a su disposición para colaborar en el castigo de los "pseudo revolucionarios". ${ }^{4}$ Además queriendo colaborar con acuciosidad a combatir la rebelión, inmediatamente se dedicó a organizar las defensas sociales en el estado y a establecer servicios de información para tener oportuno aviso de los movimientos de las fuerzas denominadas infidentes y poder dar información útil al presidente. También le solicitó permiso a Obregón para organizar el Cuerpo de Rurales del estado y colocar un jefe militar capaz de organizar estas fuerzas. Lo anterior le fue concedido y se nombró al coronel Félix Ireta, quien era el jefe de la guarnición de Morelia, como responsable de formar este cuerpo, quedando desde luego comisionado al gobierno del estado. ${ }^{5}$

La situación general del estado para los primeros días de enero de 1924, ante el avance rebelde, era de gran agitación. Del bando del

Estrada, jefe militar con el mando de las fuerzas federales que operaban en Michoacán. Véase Martín Sánchez Rodríguez, Grupos de poder y centralización política en México. El caso Michoacán, 1920-1924, México, INEHRM, 1994, 203-208.

${ }^{4}$ El texto completo del telegrama de Sánchez Pineda a Obregón dice lo siguiente: "Señor General Don Álvaro Obregón, Presidente de la República.- Palacio Nacional.- Secretaría Particular.- Núm. 258.- Por informes extraoficiales me he dado cuenta de que el ex-General Guadalupe Sánchez, de Veracruz, dando pruebas de un desconocimiento completo de sus deberes como militar y en especial como un alto miembro del Ejército, ha rebeládose $[s i c]$ contra Gobierno Ud. ha venido presidiendo con verdadero patriotismo y honradez acrisolada.- Gobierno este Estado, en nombre pueblo michoacano, se permite protestar a Ud. su respetuosa adhesión como Encargado Poder Ejecutivo de la República y manifestándole hállanse dispuestos colaborar con Ud. para castigar a pseudo revolucionarios encabezan movimiento sostenido por la reacción.- En particular permítome ratificar a Ud. mi adhesión sincera y ponerme a su disposición.- Muy respetuosamente.- El Gobernador Constitucional Substituto del Estado, Sánchez Pineda.- Rúbrica”. Luis Monroy Durán, El último caudillo: apuntes para la historia de México, acerca del movimiento armado de 1923, en contra del gobierno constituido, México, José S. Rodríguez Editor, 1924, 305.

${ }^{5}$ Ibidem, p. 306-307. 
gobierno, y debido a la ausencia del general Lázaro Cárdenas como jefe de Operaciones Militares, Obregón había nombrado como sustituto al joven general norteño Manuel N. López, ${ }^{6}$ quien el 8 de enero ya se encontraba activo por la hacienda de Guaracha organizando tropas para combatir la rebelión, ${ }^{7}$ pero al siguiente día tuvo que replegarse a Tingüindín, después de destruir las vías, pues, los rebeldes traían tres trenes. El general Salvador Alvarado invitó a N. López a defeccionar, pero éste se negó. ${ }^{8}$

El sábado 19 de enero, el general Manuel N. López recibió noticias de que se acercaba, por Chucándiro y Huandacareo, Manuel M. Diéguez con 1,500 hombres para atacar Morelia. La instrucción recibida por el cuartel general era de que, haciendo una valoración de las fuerzas enemigas y las propias, se les dejaba en libertad para resistir el ataque o implementar la retirada rumbo al estado de Guanajuato. ${ }^{9}$

Sin embargo, N. López, a pesar de lo reducido de sus elementos, se aprestó a sostener la plaza considerando que con los hombres que

${ }^{6}$ Manuel N. López Rodríguez, el "Chato” López, como le llamaban sus amigos y conocidos cercanos, nació en 1894 en Jiménez, Chihuahua. Siendo muy joven se incorporó a la Revolución contra el gobierno de Porfirio Díaz el día 20 de noviembre de 1910 a las órdenes del coronel Mariano López Ortiz con el grado de teniente. Tomó participación en el asalto a la plaza de Gómez Palacio Durango, del 15 al 16 de mayo de 1911, contra fuerzas porfiristas. Con fecha 18 de junio de 1911 fue ascendido por méritos en campaña a capitán $2^{\circ}$. Obtuvo su baja el 14 de julio siguiente por considerar que había terminado el movimiento maderista. En el mes de febrero de 1912 se incorporó a las fuerzas del general Tomás Urbina, participando en la campańa contra el orozquismo en los estados de Durango y Chihuahua durante el año de 1912. De febrero de 1913 al 15 de agosto de 1914 concurrió a 18 hechos de armas contra el huertismo en los estados de Durango, Chihuahua, Coahuila y Zacatecas y obtuvo el grado de coronel. También participó en la campańa contra el villismo durante los ańos de 1916 y 1917. Fue ascendido a jefe del 770 Regimiento de Caballería en julio de 1919. En enero de 1924, Manuel N. López era ya general y jefe de las Operaciones Militares en Saltillo, Coahuila, cuando fue nombrado, por el presidente Obregón, jefe de las Operaciones Militares en Michoacán en sustitución del general Lázaro Cárdenas. AHSDN, Cancelados, exp. del general Manuel N. López, núm. XI/III/3-2815 (en adelante MNL/ XI/III/3-2815).

${ }^{7}$ Ibidem.

${ }^{8}$ Ibidem. Manuel N. López se hizo cargo de la xx Jefatura de Operaciones Militares de Michoacán el 16 de enero de 1924, la cual le fue entregada por el general Rafael Sánchez. Oficio del general Manuel N. López al presidente municipal de Morelia del 16 de enero de 1924. Aнмм, fondo Siglo xx, caja 304, año de 1924, exp. 49.

${ }^{9}$ Véase Nazario Medina Domínguez, La última batalla, Morelia, Editorial Erandi, $1968,119$. 
tenía y la situación geográfica de Morelia, que era ventajosa para la defensa por estar situada en una loma, podría resistir el ataque. Inicialmente, Diéguez avanzó sobre las cercanías de Morelia con sus hombres, suponiendo que le serían suficientes para tomar la plaza; las demás fuerzas se quedaron en Acámbaro cubriendo la retaguardia y esperando noticias del triunfo para avanzar de inmediato sobre la capital de la República. ${ }^{10}$ La defensa de Morelia se estableció con un total de 800 hombres integrados de la siguiente manera: 500 de sus propias fuerzas; las del Primer Cuerpo Rural comandado por el coronel Félix Ireta y como subjefes el teniente coronel Manuel Castillo y el mayor Rubén Sotelo; las defensas civiles de Huetamo al mando de José María Sánchez Pineda, hermano del gobernador; las defensas de Cuispio, al mando de Agustín Córdova; y 50 hombres de la gendarmería de Morelia encabezados por Efraín Pineda que había sustituido a Rafael Márquez como jefe de la policía. ${ }^{11}$

Manuel N. López distribuyó sus fuerzas fijando los siguientes puntos: el cuartel general en Palacio de Gobierno donde él se quedaría acompańado de su escolta, del jefe de su Estado Mayor, coronel Manuel Ávila Camacho, y del gobernador y un grupo de civiles que integraban la administración y algunos colaboradores y simpatizantes. ${ }^{12}$ En el templo de San Diego se ubicó al frente el general

${ }^{10}$ Los defensores de Morelia resistieron los primeros ataques del contingente comandado por Diéguez, y hubiera resultado difícil tomar la ciudad si no hubiera sido por la gran cantidad de refuerzos rebeldes que llegaron hasta sumar un número de aproximadamente 6 mil hombres en total para lanzar el ataque final. Luis Monroy Durán, El último caudillo: apuntes para la historia de México, acerca del movimiento armado de 1923, en contra del gobierno constituido, México, José S. Rodríguez Editor, 1924, 310.

${ }^{11}$ Luis Monroy Durán asevera que fueron 750 hombres los que defendieron la ciudad de Morelia mientras que Alberto Oviedo Mota señala el dato de mil 400 hombres. Por su parte, Nazario Medina que fue partícipe de los acontecimientos refiere que eran cerca de 800 inicialmente y a los que habría que sumar los contingentes que llegaron poco después, como los 150 hombres del general Cecilio García y otros 150 del general Espiridión Rodríguez. Ibidem, p. 308, 310 y 314; y José Manuel López Victoria, Biografía de Alberto Oviedo Mota, Morelia, umsnh, 1983, 138. Nazario Medina Domínguez, op. cit., p. 119.

${ }^{12}$ Acompańaron al gobernador el licenciado Silvestre Guerrero, secretario general de Gobierno, José Alvarado Díaz, tesorero general del estado, Filiberto Malagón, contador, licenciado José Rebolledo, procurador general de Justicia, diputado Ricardo Adalid, Marcelo Pineda, oficial mayor de gobierno, Miguel Adalid, jefe de la sección de estado, Alejandro Mc Swiney, Luis Díaz, licenciado Eduardo Hernández Garibay, secretario 
Cecilio García que llegó de refuerzo con un grupo de 150 hombres, entre ellos sus tres hijos a los que se les comisionó defender el edificio de la Penitenciaría (situada al norte del Bosque de San Pedro en los terrenos donde actualmente se ubica la Facultad de Odontología) y el convento de la Visitación (actualmente el edificio que ocupa la Cruz Roja de Morelia). En el templo de San Francisco y el edificio contiguo que servía como Inspección General de Policía se quedó como responsable Efraín Pineda, primo del gobernador. En el Cuartel de las Colonias (hoy sede de la xxi Zona Militar de Morelia) ${ }^{13}$ que se encuentra frente al lugar donde principia el Acueducto, se colocó el coronel Luis de la Sierra ${ }^{14}$ y como su segundo Nazario Medina, ${ }^{15}$ ahí también se encontraba el coronel Maximino Ávila

particular del gobernador, licenciado Celso Troches, Antonio Navarrete, Donato Guevara, José María Sánchez Pineda, Jesús Sánchez Pineda, profesor Aureliano Esquivel, profesor Alberto Bremauntz, entre otros varios. Luis Monroy Duran, op. cit., pp. 312-313.

${ }^{13}$ Los antecedentes del edificio, que hoy alberga al Cuartel General de la Xxi Zona Militar, se remontan al año de 1902, cuando el general Porfirio Díaz emitió un acuerdo donde se dispuso que se construyera un Cuartel de Caballería en la plaza de Morelia, Mich. Tras la adquisición de los terrenos, el 16 de julio de 1904, se iniciaron los trabajos de construcción, se inaugura la obra el 2 de abril de 1908, fecha en que fue ocupada por personal militar; algunos años después, en 1911, el edificio recibió el nombre de "Cuartel Vasco de Quiroga”. Sergio Tirado Castro, Casas y familias de Morelia remembranzas de la cantera, México, H. Ayuntamiento de Morelia, Consejo de la Ciudad de Morelia, Secretaría de Cultura, Gobierno del Estado de Michoacán, Ediciones Papiro Omega, 2010, 136-137.

${ }^{14}$ Luis de la Sierra, originario de Tecamachalco, Puebla, revolucionario en el bando constitucionalista desde 1913, asciende a coronel en 1916 y en 1924 es ascendido a general por sus méritos en la campańa contra los delahuertistas. Archivo Histórico de la Secretaría de la Defensa Nacional (en adelante AHSDN), fondo Cancelados (en adelante Cancelados), exp. del general Luis de la Sierra, núm. D/III/3-1968.

${ }^{15}$ Nazario Medina Domínguez nació en Tacámbaro el 18 de agosto de 1890 . Estudió en el Colegio de San Nicolás (1904). En octubre de 1910 ingresó al Colegio Militar. En marzo de 1913 se le expide despacho de teniente táctico de artillería permanente y se le incorpora en el 1er. Regimiento de Artillería. En septiembre de 1913 se le asciende a capitán $2^{\circ}$ en el Ejército Federal. Capitán $1^{\circ}$ en el Ejército Constitucionalista en 1914. En 1920 y 1921 combatió en las fuerzas del general Amaro, fue jefe de la guarnición de Saltillo, Coahuila, Matamoros y Nuevo Laredo, Tamaulipas. En diciembre de 1924 se le comisionó en la jefatura de operaciones militares de Michoacán y participó en la defensa de Morelia, donde fue hecho prisionero. Escapó y se presentó con Obregón en Irapuato. Fue ascendido a coronel táctico de caballería permanente en febrero de 1924 por su participación en la defensa de Morelia. Entre otros cargos que desempeńó estuvieron los de jefe de la guarnición de la ciudad de México. jefe del departamento de infantería de la 
Camacho. En este punto se concentraron los 250 mil cartuchos de reserva que se tenían. Además, se procedió a resguardar los templos y edificios siguientes: de Lourdes, San Juan, Plaza de Toros y Colegio Salesiano, San José, del Carmen, Las Rosas, La Merced, del Prendimiento y la Escuela de Artes y Oficios, San Agustín, San Francisco, Capuchinas, Las Monjas, la Catedral y el Palacio Municipal. También se construyeron trincheras en las esquinas de Palacio de Justicia, Farmacia "Elizarrarás", Puerto de Liverpool, Administración del Timbre, Administración de Correos, "La Cruz", Farmacia "Reynoso", "El Paraíso" y Farmacia la "Equitativa".

El general N. López cometió un grave error desde el punto de vista táctico, pues, dispuso un buen número de fuerzas de línea como retén en el Cuartel de las Colonias y ahí concentró la mayor cantidad de municiones disponibles, aunque era un lugar muy alejado de los demás puntos. También estableció para la defensa un perímetro muy extenso y retenes muy diseminados, sin verdaderos lazos tácticos que debían unirlos para que auxiliándose unos a otros se abastecieran oportunamente de municiones. ${ }^{16}$

El general Diéguez habló por teléfono desde la hacienda de la Soledad, a cinco kilómetros de Morelia, con el general Manuel N. López. Le propuso que rindiera la plaza y ante su negativa lo invitó a que el combate se realizara en los lomeríos que se encuentran entre la ciudad y el cerro del Punhuato para evitarle penalidades a la población moreliana. No hubo ningún arreglo. ${ }^{17}$

\section{Se inicia el ataQue}

El 21 de enero se avistaron los primeros contingentes rebeldes en las Lomas de Santiaguito, hacia el norte y sobre el camino que va a la hacienda de la Soledad. Su caballería maniobraba con bastante pre-

Secretaría de Guerra y jefe del Estado Mayor Presidencial de Pascual Ortiz Rubio. En 1949 fue ascendido a general de división y se retiró del ejército al cumplir con la edad requerida. Escribió La última batalla. Falleció en Morelia, el $1^{\circ}$ de marzo de 1965. AHSDN, Cancelados, exp. del general Nazario Medina Domínguez, núm. x/III/1-323.

${ }^{16}$ Luis Monroy Durán, op. cit., p. 309.

${ }^{17}$ La narración completa del diálogo entre los dos generales descrita por un testigo presencial en Nazario Medina Domínguez, op. cit., p. 119-121. 
cisión en terrenos de la mencionada finca, desde la cual se iniciaron los reconocimientos, destacando al galope 400 jinetes que llegaron hasta las márgenes del río Grande. Ahí se cruzaron los primeros tiros con los defensores parapetados en los templos de San José, San Juan y el Carmen. Los atacantes sufrieron algunas bajas y se replegaron hasta el lugar donde estaban sus avanzadas. Los defensores pudieron rectificar sus tiros y trataron de establecer el lazo táctico entre sus puestos de esa parte norte de la ciudad. Con este primer enfrentamiento se consiguió poner en alarma a los pacíficos habitantes de Morelia, los cuales temerosos y angustiados, se refugiaron en sus casas para no volver a salir en varios días. Es importante señalar que la mayoría de la población moreliana no tomó partido por la rebelión y aunque no participó activamente al lado de los gobiernistas en la defensa de la ciudad, tuvo una actitud solidaria con ellos cuando fueron vencidos y algunos buscaron resguardo y protección en las casas particulares. ${ }^{18}$

La noche del lunes 21 de enero los rebeldes concentraron los elementos que tenían en las cercanías de las haciendas de Queréndaro y Atapaneo, atacando en la mañana del 22 las posiciones establecidas en el Cuartel de las Colonias, Santuario de Guadalupe, templos de Lourdes, San Juan, San José y el Carmen, logrando entonces, por su abrumadora fuerza numérica, rebasar varios puntos de las líneas de defensa, teniendo necesidad para ello de minar algunas casas. Por el rumbo noreste lograron avanzar hasta la Plaza de Toros (donde hoy está el hotel "Vistaexpress" en la esquina de la calle Aquiles Serdán y Amado Nervo) y se posesionaron de ella tras un durísimo combate. ${ }^{19}$

${ }^{18}$ Entre estos ejemplos tenemos los siguientes: el canónigo Francisco Nieto, el presbítero don José Mier, la familia de la señora Soledad del Moral viuda de Iturbide, el señor don Pablo Oseguera que dio alimentos y medicinas para los heridos en el Hotel Oseguera, la Sra. Rivadeneyra, el Sr. Gonzalo Ojeda, Vicente Armas López, Alejandro Mc Swiney, las familias Huerta y García, la señora Aristea viuda de Martínez, Wilfrido Martínez, Salomón Rafael, Emiliano Díaz, entre otros varios, Luis Monroy Durán, op. cit., p. 325.

${ }^{19}$ Excélsior, segunda sección, México, D. F., 9 de febrero de 1924, 1. El gobernador Sánchez Pineda (y después Monroy Durán retomando esta versión), dice que en esta acción fue donde murió el general Buelna, pero Nazario Medina da otra versión que es la que referimos más adelante. 
El 22 por la mańana el cuartel general dispuso entonces que el coronel Félix Ireta hiciera una salida para atacar a los asaltantes con una fuerza de 28 hombres, llevaban además una pistola ametralladora Thompson. El empuje del coronel Ireta y los suyos fue arrollador; el mismo coronel manejó la ametralladora con la cual causó estragos en las fuerzas rebeldes, logrando rechazarlas en esta acción hasta la Loma del Zapote a tres y medio kilómetros. ${ }^{20}$ Los rebeldes construyeron pequeñas fortificaciones y contrajeron su línea de fuego, emprendiendo de nueva cuenta furiosos ataques contra el Cuartel de las Colonias y el templo de San Diego, pero no pudieron hacer nada. Ese mismo día 22 como a las 14 horas llegó de Uruapan el general Espiridión Rodríguez con 150 soldados y reforzó los retenes que defendían las posiciones de San Juan y Plaza de Toros que habían sido recuperadas. También ese mismo día cuando la lucha entre los dos bandos se desarrollaba por todos los puntos de la ciudad, un aeroplano blindado tiroteó con ametralladora algunas posiciones del enemigo y arrojó a las calles un mensaje del presidente Obregón, ordenando la desocupación de la plaza. Pero una junta de guerra que se reunió para tratar el caso resolvió continuar la defensa, toda vez que para desocupar la ciudad en esos momentos hubiera sido preciso sacrificar a casi todos los combatientes. ${ }^{21}$

${ }^{20}$ Monroy Durán, op. cit., p. 314. En la Loma del Zapote se ubicaba una colonia agrícola formada por exmilitares, la mayoría de los cuales se presentaron en Morelia el 19 de enero ante el general Manuel N. López para ofrecerle sus servicios, quien les ordenó que regresaran a la Colonia, fueron hechos prisioneros en el trayecto, algunos de ellos, por los rebeldes al mando del general Manuel M. Diéguez, lograron fugarse e incorporarse a la referida Colonia y otros regresaron a defender Morelia. De esta Colonia se unieron a los rebeldes el teniente coronel Ignacio Salinas, teniente Luis Mendoza y subtenientes Juan de Dios Ocampo y Zenón García. Informe del general Rafael Aguirre encargado del Departamento de Colonias Agrícolas Militares de la Secretaría de Guerra y Marina al general subsecretario de Guerra y Marina, 25 de marzo de 1925, Archivo General de la Nación (en adelante AGN), fondo Presidentes Obregón-Calles (en adelante FO-C), exp. 101-R-2-B-1, fs. 116.

${ }^{21}$ Aparte del señalamiento que hace Monroy Durán en su crónica del sitio de Morelia no hemos encontrado más referencias al mensaje que envió Obregón con este aeroplano, pero si tenemos un telegrama enviado por el presidente este mismo día al general Manuel N. López y que se puede suponer coincidía con el que se mandó desde el aeroplano. El telegrama dice lo siguiente: "Celaya, Guanajuato, enero 22 de 1924. Gral. M. N. López.- Grueso columna enemiga entró ayer Acámbaro y suponemos avanzará sobre Morelia. En ese caso, conviene que usted, salvando todos sus elementos, procure hacer 
El martes 22, ya por la tarde, la situación se calmó un poco. El gobernador Sidronio Sánchez refiere sobre aquellos momentos:

Aquella tarde se pasó relativamente tranquila. El enemigo considerándose débil para seguir avanzando por el lado norte, comenzó a cambiar sus posiciones hacia el sur, no sin dejar pequeños contingentes con órdenes de tirotear nuestras posiciones para distraer nuestra atención. Sin embargo, pudimos darnos cuenta de la maniobra que no era otra que la de esperar los refuerzos pedidos al resto de la columna rebelde que se hallaba en Acámbaro [...] En la madrugada del miércoles fue avistado el primer tren de refuerzos para los revolucionarios, precisamente por el sur y en cantidad de más de mil hombres. ${ }^{22}$

El día 23 como a las diez horas los rebeldes notoriamente desmoralizados por la resistencia que encontraron, pero reforzados con los contingentes que hasta ese momento habían permanecido en Acámbaro, emprendieron nuevos ataques contra las posiciones de la Merced y Escuela de Artes y Oficios, es decir, en puntos extremos de los que habían atacado inicialmente, con la idea de encontrar menos resistencia, pero también fracasaron y fueron rechazados hasta los terrenos del Hospital General y de la Estación de Ferrocarril. El día 23 fue cortada el agua de los filtros que abastecía a la ciudad, así como la energía eléctrica, teléfono y telégrafo. Por la noche los rebeldes recibieron más refuerzos. Sobre esto señala Simón Cortés Vieyra en sus memorias:

El 23 llegué con mi gente a ésta. Ya Morelia estaba sitiada por fuerzas del general Enrique Estrada [...] ahí en Santa María repartí parque que me

una retirada oportuna, para que usted pueda así, a la salida de ellos, controlar de nuevo el Estado con los elementos de que dispone, pues es seguro que los infidentes tendrán que marchar precipitadamente para defender su base, al sentir el avance de nuestras fuerzas que seguirá sin interrupción su marcha sobre Guadalajara. Para que infidentes no puedan hacer su marcha en ferrocarril de Morelia a Ajuno, deberá usted mandar destruir convenientemente la vía y alejar todo el material rodante que pudiera estar al alcance del enemigo. Afmte. Presidente República Álvaro Obregón”. Luis Monroy Durán, op. cit., pp. 310-315, AHSDN, Cancelados, MNL/XI/III/3-2815.

${ }^{22}$ Excélsior, segunda sección, México, D. F., 9 de febrero de 1924, 1. 
había proporcionado el general Estrada. Dejé a los que traían 30-30 y demás calibres inferiores cuidando la caballada. Salimos de Santa María como a las once de la noche. En el Parque Juárez nos organizamos e intercalamos un soldado de línea con uno de los nuestros. A mí me tocó atacar por el lado de Capuchinas. ${ }^{23}$

\section{La Muerte Del general Rafael Buelna}

\section{Y LA OFENSIVA FINAL}

El mismo 23 de enero el famoso general Rafael Buelna se encontraba situado en la hacienda de Atapaneo y al escuchar el nutrido tiroteo ocasionado por el intento de los sitiados de romper el cerco, montó a caballo y acompañado de su Estado Mayor se encaminó al lugar de la lucha. Mandó reforzar sus contingentes y llegó hasta la cerca de piedras desde donde atacaban a los defensores del Cuartel de las Colonias. En lo más reñido del enfrentamiento mandó que le trajeran su caballo y lo montó para dirigir a sus combatientes. De inmediato lo alcanzó una bala en el estómago que se alojó en la espina dorsal y se desplomó a tierra mortalmente herido. Fue rescatado con la mitad del cuerpo paralizado; cubierto de lodo y sangre y en agonía. A los pocos minutos murió. ${ }^{24}$

${ }^{23}$ Este singular personaje hace una interesante y pintoresca narración de cómo se desarrolló este ataque y las peripecias que tuvieron que efectuar para lograr tomar las posiciones del enemigo horadando las casas circunvecinas a la inspección de policía hasta que coparon al enemigo y lo obligaron a rendirse ante la superioridad numérica. Memorias de Simón Cortés Vieyra (1880-1963), Introducción y notas de Álvaro Ochoa Serrano, Morelia, Gobierno del Estado de Michoacán, 2007, 35-38.

${ }^{24}$ Nazario Medina Domínguez, op. cit., pp. 123 y 134-137. Un participante de estos hechos relata que "El segundo día del sitio, habiendo iniciado un ataque sobre el Cuartel de las Colonias, personalmente con una columna, el Gral. Buelna, fue herido mortalmente casi a unos veinte metros de dicho cuartel. Se le trasladó a los trenes del General Estrada que se hallaba en la hacienda de Atapaneo y en dicho lugar murió siendo sepultado en el patio de la Hacienda y más tarde exhumado para llevarlo a Morelia". "Informe sobre la insurrección delahuertista con datos proporcionados por el señor José María Moreno (excoronel del Ejército)" (en adelante Informe sobre la insurrección delahuertista) en Archivo Histórico de la Universidad Nacional Autónoma de México (AHUnam), fondo Amado Aguirre (en adelante FAA), caja III, exp. 9, fs. 48-50. El 28 de enero cuando se incorporaron nuevos elementos dispersos de Morelia, uno de ellos, el capitán Martín Tapia, tal vez buscando un ascenso, dijo falsamente que él fue quien mató al general Buelna cuando este jefe 
Después de la muerte de Buelna, conferenciaron Diéguez y Estrada para discutir la situación general; éste último, desmoralizado y abatido, opinó que se retiraran inmediatamente de Morelia; pero Diéguez le aseguró que Morelia sería tomada al siguiente día. Estrada se retiró a sus trenes en Atapaneo, y Diéguez ordenó un asalto general a la Plaza para las doce de la noche de ese día. ${ }^{25}$

A la una de la mańana del jueves 24 , los atacantes rompieron el fuego e iniciaron el asalto final con todas sus fuerzas. Marcelo Pineda, oficial mayor de gobierno, fue alcanzado por una bala en el pecho cuando desde la azotea de Palacio de Gobierno trataba de observar el campo de batalla con unos binoculares. Ante la mayoría numérica, pues la diferencia era de 10 atacantes por cada uno de los defensores, y la falta de abastecimiento de parque, los retenes defensivos comenzaron a ser tomados uno tras otro.

Éstos fueron tal vez los momentos más álgidos de la batalla entre sitiadores y defensores de la ciudad de Morelia, así lo describe el gobernador Sánchez Pineda:

Conforme despuntaba el día crecía el horror de la lucha y se hacía más patente la desigualdad con la que peleaba nuestras tropas contra un enemigo cuatro o cinco veces mayor. Las calles se hallaban completamente desiertas y hubiera podido creerse que Morelia carecía de habitantes, como no fueran los soldados que cruzaba rápidos, con la ira retratada en los semblantes, el arma empuñada y la blasfemia en los labios. ${ }^{26}$

Por el poniente los rebeldes habían hecho grandes progresos batiendo al retén establecido en el templo de la Merced. El Cuartel

rebelde se encontraba posesionado de la plaza de toros. Afirmó que usó una ametralladora contra los atacantes. El Universal, México, D. F., 29 de enero de 1924, 1 y 6.

${ }^{25} \mathrm{Ibidem}$. Según el testimonio del coronel estradista José M. Moreno, en los primeros días del sitio a Morelia, el general Diéguez atacó por la garita de Santiaguito, pero cuando el ataque se generalizó dejó este sector bajo la responsabilidad directa de Estrada y él atacó por el rumbo del Cuartel de las Colonias y la garita de la salida a México, por Santa María atacó el general Félix Barajas y por la Huerta atacaron el coronel Arnáiz, Chávez y otras corporaciones, Informe sobre la insurrección delahuertista, fs. 48.

${ }^{26}$ Excélsior, segunda sección, México, D. F., 9 de febrero de 1924, 1. 
General se dio cuenta de la situación angustiosa de los defensores en este punto y dispuso un contraataque que efectuó el coronel Félix Ireta con treinta hombres de la guarnición federal. Con gran valentía lograron poner en completa desbandada a los enemigos, que dejaron gran cantidad de muertos y armas y una bandera que portaban. En este combate, la ametralladora Thompson se inutilizó al recibir un balazo en el disco, salvándose Ireta de una muerte segura. $\mathrm{Al}$ regresar de esta acción, Ireta recibió órdenes para que enviara un oficial a los retenes de Lourdes y Plaza de Toros con el fin de informarles que del Cuartel de las Colonias avanzaban 60 hombres llevando parque. No encontró ningún oficial y él mismo abordó un camión y recorrió la avenida Madero hasta llegar al cruce con la calle Miguel Cabrera donde estuvo a punto de caer en manos de los rebeldes. Los diversos retenes pedían con insistencia que se les abasteciera de parque y el cuartel general dispuso que una escolta de la guarnición lo transportara abriéndose paso, si era preciso, entre las filas de los rebeldes, pero éstos ya habían invadido el Bosque Cuauhtémoc, en tal número, que se hizo imposible cumplir dicha orden. El coronel Ireta, en cuanto regresó al Palacio de Gobierno, fue enviado nuevamente a batir a los rebeldes que se habían apoderado de San Agustín y hacia allá se encaminó llevando fuerzas de las defensas sociales de Huetamo al mando de José María Sánchez Pineda, logró una nueva victoria al derrotar al enemigo y volvió a ocupar aquella posición. ${ }^{27}$ Sin embargo, este triunfo no fue suficiente para contener a los rebeldes.

El primer puesto que cayó fue el templo de Capuchinas.

Su situación cercana al asilo de nińos, edificio muy amplio que fue aprovechado por los rebeldes para avanzar hizo que desde allí se dirigiera un fuego certero contra los defensores del Fortín de Capuchinas capturándolo a las cuatro de la mańana [...] Los defensores no tuvieron un solo momento de reposo, en tanto que los atacantes que peleaban dos o tres horas eran remplazados por otros de refresco. Uno a uno fueron cayendo los puestos militares de Morelia, dándose el caso de que se combatiera en las calles,

${ }^{27}$ Luis Monroy Duran, op. cit. p. 312. 
desde las azoteas, tras de cualquier muro o cualquier árbol, sin pedir cuartel los defensores y sin concederlo los rebeldes, en forma sangrientísima, cual si lucharan enemigos separados por odios ancestrales. ${ }^{28}$

Ante la inminente derrota se corrieron entonces órdenes para que las guarniciones sostuvieran sus posiciones algún tiempo más; se llamó a los escasos elementos civiles y militares que se hallaban parapetados en las azoteas del Palacio de Gobierno y se formó una raquítica columna de caballería formada con la escolta del general López y rurales del estado. En total unos 50 soldados.

A esta pequeña fuerza se unieron los generales José Aceves, el coronel Júpiter Ramírez, ${ }^{29}$ el teniente coronel Felipe Páramo, mayor J. Olivares, capitán primero Jesús Corona y el gobernador Sidronio Sánchez Pineda con un buen número de civiles. Ese último día y de ma-

${ }^{28}$ Excélsior, segunda sección, México, D. F., 9 de febrero de 1924, 1. Sobre la toma de la posición del templo de Capuchinas narra nuestro multicitado Simón Cortés: "Entramos por donde ahora es la plaza de toros (Rancho del Charro). Al llegar al Puente Colorado nos desorganizamos por la balacera por todos lados. Al pasar al otro lado del río [...] juntamente con la demás gente, nos repegamos [sic] a las paredes de las casas hasta llegar a la torre de Capuchinas. Llegamos al zaguán. Nos marcaron el alto las fuerzas que estaban en la torre. Les contestamos que éramos refuerzos que les mandaban, que nos abrieran y, acabando de abrir el soldado que lo hizo, intentamos cogerlo [...] nos fuimos sobre él. Subimos el primer piso de la torre; luego puso alerta a sus compañeros, que nos esperaron con una lluvia de balas cerrándonos el paso a fuego. No pudimos avanzar más, quedándonos en el segundo piso de la torre. Nos hicieron fuego también en las azoteas, que contestamos por las ventanas y puertas. [...] les matamos algunos y se sumieron no pudiendo más [...] Luego que dominamos ahí, cambió la situación para nosotros. Luego a tientas dimos con un piano. Iba con nosotros uno que sabía tocarlo. Cantando y dedicándoles canciones nosotros a nuestros contrarios que estaban en el tercer piso de la torre, les decíamos que se rindieran; y nos contestaban con insolencias [...] Estaban borrachitos: nos decían que tenían parque para tres meses. [...] Hasta que amaneció hablamos con el general Arnaez ya en serio para que se rindieran [...] resolvieron rendirse poniendo como condición que tenía que ser con el general Rentería. Como él no estaba se les ofreció seguridad respetándoseles sus vidas”. Memorias de Simón Cortés..., pp. 35-36.

${ }^{29}$ Júpiter Ramírez nació en 1893, originario de Piedras Negras, Coahuila, ingresó como voluntario en las filas del constitucionalismo en junio de 1913 en el regimiento "Libres del Norte". Ascendido a coronel en 1920. Jefe del Estado Mayor del general Antonio Pruneda en ese mismo ańo. AHSDn, Cancelados, exp. del coronel Júpiter Ramírez núm. R/23-II-78. 
nera discreta, el gobernador dio orden de que pusieran a disposición de los que habían estado con él, sendas bolsas de mil pesos en plata. ${ }^{30}$

Se INTENTA ROMPER EL SITIO

El general López resolvió ponerse al frente de la columna para intentar romper el cerco y salir de la plaza con este grupo tan reducido; el coronel Ireta no formó parte de este grupo porque había recibido órdenes de recoger a los defensores que se hallaban combatiendo en algunas trincheras de la ciudad. Cuando regresó al Palacio de Gobierno ya había salido la columna, por lo cual resolvió permanecer en ese edificio y luchar aún con los pocos hombres que allí quedaban. La columna de López salió por la puerta norte de Palacio de Gobierno, dirigiéndose bajo el fuego del enemigo hasta el jardín del Carmen, con el objeto de romper el cerco por la garita de Santiaguito. $\mathrm{Al}$ encontrar muy cerrado el sitio por esa dirección, la pequeña columna se dirigió por la calle 5 de febrero hasta llegar a la esquina con Serapio Rendón, allí se hizo un alto para reorganizarse y N. López mandó, al mayor Tapia con parte de su escolta, se adelantara para localizar las primeras posiciones enemigas por ese rumbo. El mayor cumplió lo dispuesto y luego de tirotearse largo trecho con el enemigo alcanzó a salvarse y pudo arribar días después a Irapuato. Los demás no tuvieron tanta suerte, pues el resto alcanzó la calzada México y trató de rebasar la garita del Zapote, pero en ese intento fueron muertos el mayor don Rubén Sotelo, el diputado Ricardo Adalid y su hermano, el coronel Júpiter Ramírez, Jesús Gordillo, Pedro Rodríguez y un puñado de soldados más. Quedaron heridos de gravedad, Leobardo Sotelo, ayudante del gobernador, Lamberto Pineda y otros más que fueron rematados por los soldados.

Fueron apresados José María Sánchez Pineda, Salvador Ledesma y varios de los soldados combatientes. El general López fue cap-

${ }^{30}$ Antonio Navarrete, periodista muy cercano al gobernador, tomó una bolsa y salió por atrás de Palacio de Gobierno, pero apenas pudo llegar a la casa de enfrente de Gonzalo Ojeda, que era su conocido; ahí dejó la bolsa y se escapó por las calles. Posteriormente quiso recogerla, pero le dijeron que se había perdido. Alberto Bremauntz, Setenta años de mi vida. Memorias y anécdotas, México, Ediciones Jurídico Sociales, 1968, 92. 
turado debido a que sufría por la herida de una pierna y no podía marchar de prisa.

Al ir avanzando la caravana, una bala hirió y derribó el caballo de Virgilio Pineda, ayudante y primo del ejecutivo, éste no quiso dejarlo pues podía ser asesinado por los soldados enardecidos así que detuvo su caballo y trató de montar en las ancas de su animal al muchacho, con tan mala suerte que éste al agarrarse desesperado lo arrastró y cayeron ambos al suelo. Al ver que sus demás compañeros ya iban lejos, prefirieron pedir ayuda en una casa particular, recibieron la hospitalidad de la familia Rivadeneira y después la del señor Vicente Arenas López. Más tarde, después del 27 de enero, el gobernador y su ayudante salieron de Morelia, disfrazados de arrieros, vestidos sombrero de palma, ropas de manta y huaraches; al pasar por Indaparapeo se encontraron con una partida de rebeldes dirigida por Simón Cortés y para no ser descubiertos se durmieron en un potrero. Luego siguieron a Zinapécuaro, donde durmieron en un mesón a las orillas del pueblo y continuaron a un rancho cercano a la sierra y, por último, marcharon a pie hasta Acámbaro, que se encontraba desguarnecido tanto de federales como de rebeldes. A bordo de un automóvil se fueron a Celaya y de ahí a Irapuato donde el gobernador fue recibido con felicitaciones por el presidente Obregón. ${ }^{31}$

Cuando el coronel Ireta calculó que la columna expedicionaria se había abierto paso, ordenó a los hombres que con él permanecían que abandonaran el Palacio de Gobierno y procuraran salvarse, mientras que el mismo Ireta, saliendo de este edificio, pasó entre las tropas, ya triunfantes, tranquilamente y, como no lo reconocieran, logró penetrar a una casa amiga para albergarse. Después logró escapar de la ciudad y se dirigió a Maravatío para ponerse a las órdenes de Obregón. ${ }^{32}$

El coronel Manuel Ávila Camacho se contaba entre los que quedaban en el Palacio, huyó y fue escondido en la casa de José María Hernández, padre de su ayudante, Alfonso Hernández, donde permaneció hasta el 28 de enero, fecha en la que salió hacia Acámbaro

${ }^{31}$ Excélsior, segunda sección, México, D. F., 9 de febrero de 1924, 1.

${ }^{32}$ Luis Monroy Durán, op. cit., p. 322. 
con un salvoconducto que le proporcionó el general José Rentería Luviano, jefe de las fuerzas rebeldes en Michoacán, por gestiones que hizo ante él su subordinado Alfonso Hernández, quien lo salvó dos veces. ${ }^{33}$

\section{Cae la plaza de Morelia}

A las 15 horas del 24 de enero de 1924 apareció en el balcón del Palacio de Gobierno una bandera blanca pidiendo la suspensión de hostilidades, y un repique a vuelo de las campanas de la Catedral anunció la caída de la plaza. Al mismo tiempo, los rebeldes habían tomado por la fuerza el Palacio Municipal donde murió el capitán Miguel Llerena; la iglesia de San Agustín, la Escuela de Artes y Oficios (hoy Palacio Clavijero), Las Rosas, las Monjas y la Catedral. A las 16 horas cayó la Inspección de Policía que estaba ubicada en el templo de San Francisco. Ahí Efraín Pineda resistió dos días hasta que, mal herido y visto el asunto perdido, se escondió en una casa de las cercanías. ${ }^{34}$ Sobre la toma de la inspección de policía refiere Simón Cortés Vieyra:

Yo, por mi parte, me puse al frente [...] acordando con el general Arnaiz mandar avanzadas por donde antes era el Gallo Negro (zona de tolerancia) con barras y picos agujerando las paredes. Cuando llegamos a la última cuadra, ya para llegar a la Inspección de Policía, mandamos a unos por las azoteas arrastrándose de pecho hasta llegar frente a la Inspección poniendo una contraseńa con los que iban por las azoteas y los que íbamos agujerando las paredes para que a una señal determinada diéramos el asalto. [...] A un tiempo, los que iban por las azoteas y nosotros cerramos el fuego. Inmediatamente se rindieron. [...] Enseguida nos abrieron todas las puertas de la Inspección. Entramos y los soldados nuestros, a cual más, a coger

${ }^{33}$ Nazario Medina Domínguez, op. cit., p. 148.

${ }^{34}$ Un hijo de Efraín Pineda afirma que estando su padre herido y escondido en una casa particular cerca del templo de San Francisco, lo encontró el capitán Aldo Betanzos, quien lo iba a asesinar pero lo salvó su tío el general Juan Pablo Pineda de la Garza, hombre de avanzada edad que formaba parte del Estado Mayor de Estrada. Él le permitió escapar. Efraín Pineda Guerrero, Crónica de los años muertos, Morelia, Edición del autor, 2007, 168-175. 
caballos, monturas, rifles, pistolas y hasta cuchillos, escogiendo lo mejor. Había reguero de parque en todas partes, de todos calibres. Una vez tomada esa posición mucha gente pacífica se avanzó todo lo que quería. ${ }^{35}$

San José y la Escuela Normal para Varones se resistieron, pero fueron aniquiladas por un enemigo superior en número. Igual suerte corrieron San Juan, la Plaza de Toros, Lourdes y San Diego, donde se encontraba el general Cecilio García quien peleó hasta agotar el parque. El retén de la Penitenciaria se replegó en el Cuartel de las Colonias. En la Merced y el Carmen, ante la evidente superioridad, entraron en pláticas con el enemigo, y Enrique Estrada les concedió al comandante y a sus soldados que salieran con sus armas y se les dieron garantías sobre su vida.

El último reducto en caer, hasta las ocho de la noche del 24, fue el Cuartel de las Colonias defendido por el coronel Luis de la Sierra, quien ignoraba lo que estaba sucediendo en la ciudad. Los vencedores concentraron contingentes alrededor del cuartel y enviaron a uno de los prisioneros, al teniente Salvador Ledesma, para que informara a sus compañeros y los invitara a rendirse, carecían de agua y alimentos y sus heridos no tenían atención médica por lo que el sacrificio era inútil. Se pactaron enseguida las condiciones en que habrían de rendirse, se entregaron las armas y municiones, quedando todos prisioneros ahí mismo. ${ }^{36}$

${ }^{35}$ Memorias de Simón Cortés..., p. 37-38.

${ }^{36}$ El 24 de enero por la mañana, El Universal cabeceó en su primera página: "Porqué fue ocupada la capital de Michoacán”. En la nota Obregón dijo que intencionalmente se evacuó la plaza para evitar que los rebeldes volvieran a su base de operaciones. "Los rebeldes pretendían amagar Morelia para que los federales distrajeran fuerzas en su defensa pero el plan fue descubierto y se ordenó que se evacuara para que ellos la tomaran. El enemigo lo hizo y entonces se ordenó a las fuerzas de Amaro que avanzaran y llevan de ventaja tres jornadas. Los rebeldes en contra marcha no podrán regresar a su base de operaciones sin presentar combate". Cuando se le preguntó al presidente Obregón sobre la importancia de la toma de Morelia éste contestó: "Militarmente carece de importancia porque tienen que abandonarla y el general López, con las fuerzas a su mando, que evacuaron dicha plaza, volverá a ocupar el estado y a restablecer todos los servicios. En cuanto a elementos de guerra, no pueden obtener ningunos, y en lo que a dinero se refiere, éste lo sacarán a sus propios partidarios, quienes quedarán muy satisfechos de ayudar a su causa”. El Universal, México, D. F., 24 de enero de 1924, 1 y 8. Hasta aquí Obregón hablaba de una "evacuación de la plaza" lo cierto era que se había defendido tenazmente por las 


\section{La muerte de los generales Manuel N. López y Cecilio García}

El general Manuel N. López, ya prisionero, fue llevado a la presencia del general Diéguez

quien le recriminó por su conducta, advirtiéndole que por culpa de él se había derramado tanta sangre y que si hubiese secundado el movimiento, hubiera tenido las consideraciones y merecimientos del caso; pero el Gral. López repitió con gran entereza que, era soldado y sabía cumplir con su deber [...] Diéguez le pidió entonces que mandara decir a los pocos soldados que aun hacían resistencia que se rindieran puesto que él, el Gral. López, estaba ya preso. López se negó también. ${ }^{37}$

Tomada la plaza se le internó en el Hospital Militar para que fuese atendido en sus heridas, por orden de Estrada y Diéguez; pero al cuarto día de permanencia en dicho establecimiento, fue trasladado al Palacio de Gobierno por orden de los jefes Ramón Arnaiz y Alfredo C. García, quienes en dicho edificio tenían establecido su cuartel. A diario discutían Arnaiz y García con el herido, tratando de convencerlo sobre la justicia y legalidad del movimiento encabezado por Estrada y De la Huerta; más nunca hicieron que el prisionero cambiase de manera de pensar, hasta que un día en que se agriaron demasiado las discusiones, Arnaiz, enfurecido por la terquedad y firmeza de N. López, sacó su pistola y le disparó cinco balazos. ${ }^{38}$

fuerzas dirigidas por el general N. López hasta que viendo la causa perdida intentaron la retirada. El general Amaya dice por su parte que Obregón al conocer oficialmente el desenlace de la batalla de Morelia "con las orejas muy rojas, que era un signo que marcaba en su semblante aquello que le disgustaba, profirió las siguientes frases: ¿A dónde iré a dar con estos jefes de valor indiscutible, pero que todo me lo descomponen al desobedecer mis órdenes?”. Juan Gualberto Amaya, op. cit., p. 46.

${ }^{37}$ Informe sobre la insurrección delahuertista, fs. 49.

${ }^{38} \mathrm{Ibidem}$, sobre el destino final del jefe de la plaza el general Nazario Medina refiere que quien le dio muerte, el día 26 de enero, fue un teniente de pésimos antecedentes apodado "El Malacate", quien por órdenes de Arnaiz, apuñaló sobre el lecho del dolor al general López. Nazario Medina Domínguez, op. cit., pp. 126-127. El presidente Obregón en una orden que expidió el 4 de febrero de 1924, para que se le diera pensión a la 
El 26 de enero, Vicente Barba y Casillas ofreció una comida en el hotel Europa al general Rentería Luviano; en la animación del convivio y ya bajo los influjos del alcohol, José Carmen Luviano, ${ }^{39}$ tío de Rentería, se le ocurrió proponer ir a matar al general Cecilio García ${ }^{40}$ y movidos por un afán de revancha él y el general Arnaiz, junto con unos veinte comensales se dirigieron a la Penitenciaria del Estado a consumar el asesinato. En el patio del edificio lo acribillaron para que después el mayor José María Elizondo cometiera un acto abominable al quemar el cuerpo y hacerlo motivo de burlas. Sólo se reconoció después el cadáver de don Cecilio porque se encontró una mano suya que portaba el anillo que tenía costumbre de llevar en ella. ${ }^{41}$

madre del general Manuel N. López, refiere que éste murió el 26 de enero en el Hospital Militar de Morelia donde se le atendía de las heridas que recibió. AHSDN, Cancelados, exp. del general Manuel N. López núm. XI/III/3-2815. A mí juicio la versión más creíble es la de que fue Arnaiz el que asesinó al general López pues el coronel José M. Moreno, quien afirma lo anterior, era gente muy cercana al general Estrada y seguramente conoció de estos hechos de manera directa.

${ }^{39}$ José Carmen Luviano García, hijo del prefecto de Huetamo, José Carmen Luviano Romero. Propietario rural. Prefecto interino de Huetamo en 1913. Presidente municipal de Huetamo en 1914, 1916, 1917 y 1923. Martínez González, Ma. Guadalupe y Salas Durán, María de Jesús, Los presidentes municipales de Huetamo: un siglo de vida politica y administración municipal 1910-2010, México, H. Ayuntamiento Constitucional de Huetamo 2008-2011, Archivo Histórico Municipal de Huetamo "Gral. Jesús Millán Nava", 2012, 56-57.

${ }^{40}$ El general Jesús Millán Nava refiere que cuando al general Cecilio García se le comisionó para atrapar a Rentería Luviano por el motivo de haberse rebelado contra el gobierno, éste fue a Huetamo con un fuerte contingente de tropas y al no encontrarlo tomó prisionero a su tío Carmen Luviano al que conminó para que entregara rendido a su sobrino o sufriría las consecuencias de la actitud asumida por aquél. Carmen Luviano hombre pacífico y de hogar se espantó y pidió permiso a García para ir a buscar a su sobrino, pero al llegar a su casa alarmado y comprendiendo el peligro en que se encontraba se escapó con sus hijos para unirse a la rebelión. Por lo anterior, Carmen Luviano le tenía cierto rencor al general Cecilio García que con su actitud lo había obligado a irse también al monte. Jesús Millán Nava, La Revolución Maderista en el estado de Guerrero y la Revolución Constitucionalista en Michoacán, México, edición del autor, 1968, 288.

${ }^{41}$ José Manuel López Victoria, op. cit., p. 143-144 y Luis Monroy Durán, op. cit., p. 322. En fechas posteriores y para efectos de inhumar el cadáver del general Cecilio García se levantó un acta ante un juez el día 8 de marzo de 1924, donde los testigos Horacio Pineda, José María Sánchez Pineda y Daniel Franco López declararon que les constaba que el general Cecilio García "falleció de heridas por proyectil de arma de fuego, a las veintitrés horas del día veintiséis de enero del presente año, en la Penitenciaría del Estado 


\section{EL PERDÓN A LOS PRISIONEROS Y EL FUNERAL de Rafael Buelna}

Gran parte de los jefes y oficiales hechos prisioneros fueron trasladados al Cuartel de las Colonias. Eran alrededor de 95. Ahí el general Enrique Estrada habló con ellos y dejó en libertad a la gran mayoría con la única condición de que juraran, a través de la firma de un documento, no volver a hacer armas en contra del movimiento, a lo cual sólo se negaron a firmar el mayor Rafael Cházaro Pérez, los tenientes coroneles José Tafolla Caballero, Anselmo Macías Valenzuela y Nazario Medina, quedando prisioneros ahí mismo, aunque a los pocos días lograron fugarse. ${ }^{42}$ El alto mando rebelde, después de publicitar profusamente el documento firmado por los oficiales perdonados en las esquinas de la ciudad, expidió una amplia amnistía para que todos los demás oficiales gobiernistas que se encontraban en la ciudad escondidos pudieran salir de la misma, ya sin invitarlos a firmar el documento como requisito. ${ }^{43}$

El 25 de enero por la tarde se llevó a cabo el sepelio del célebre y querido por la tropa general Rafael Buelna, El Grano de Oro, con la presencia de su viuda, el general Estrada, Manuel M. Diéguez,

de esta Capital. Los suscritos testigos hacen constar que trasladados al lugar de los acontecimientos citados, con fecha 24 del pasado febrero, encontraron en el segundo patio del establecimiento de referencia, a una distancia de 10 metros de la puerta de entrada de dicho patio y con dirección al sur, el lugar en el que seguramente fue incinerado el cadáver del expresado general García. Para identificar los restos, corrimos la suerte de encontrar algunas prendas personales del extinto y que son las siguientes: un pito de cuerno que usaba el general para llamar a su asistente, una mancuernilla, un puente de oro con un premolar artificial y un canino natural; un anillo con sus iniciales y algunos otros objetos, que, reconocidos de su propiedad, acusan la incineración del cadáver, ya que el sitio donde fueron encontrados está del todo impregnado de grasa”. AHSDN, Cancelados, exp. del general Cecilio García.

${ }_{42}$ Según el testimonio de Nazario Medina el documento que los prisioneros tenían que firmar para salir libres decía más o menos lo siguiente: "juro bajo mi palabra de honor y de soldado, no volver a hacer armas en contra del ejército de la legalidad, etc.” Lo anterior tenía que ver con el Art. 405 del Código de Justicia Militar que señalaba que cuando un oficial del Ejército Mexicano cayera en poder del enemigo y se obligara a no volver a tomar las armas contra éste quedaría inhabilitado por diez ańos para el servicio. Nazario Medina Domínguez, op. cit., p. 141-142.

${ }^{43}$ Ibidem, p. 151. 
Rentería Luviano y un gran número de oficiales, soldados y público en general. ${ }^{44}$

\section{El SAQUeO DE LA CIUDAD Y EL NOMBRAMIENTO \\ DE AUTORIDADES POR LOS JEFES DELAHUERTISTAS}

El ayuntamiento de Morelia se condujo con lealtad al gobierno y mantuvo lo más posible funcionando los servicios públicos, pero, finalmente, ante el caos que se vivía, resolvió separarse de sus puestos mientras durara la ocupación de Morelia. Enseguida del triunfo de los rebeldes, muchos soldados ebrios y ávidos de conseguir alguna ganancia recorrían las calles de la ciudad asaltando a los pacíficos ciudadanos que por alguna u otra razón tenían que salir. El corresponsal del periódico Excélsior describió esta situación:

Gran número de fuerzas permaneció en la ciudad sin ser acuartelado. La oficialidad era en extremo correcta, pero los soldados, ebrios algunos, provocaban frecuentes escándalos en cantinuchas y barrios. Los atracos callejeros se registraban en todas partes y a todas horas, a mano armada. Era la misma gente de tropa la que asaltaba. Las descargas de pistolas y rifles se escuchaban con frecuencia. Llegó a asegurarse que en dos o tres ocasiones un grupo de soldados pretendió apoderarse de guapas muchachas. ${ }^{45}$

${ }^{44}$ Los restos de Buelna estuvieron en el Panteón Municipal de Morelia hasta enero de 1931, año en que fueron trasladados a Sinaloa y reposan actualmente en la Rotonda de los Hombres Ilustres de ese Estado.

${ }^{45}$ Excélsior, México, D. F., 24 de febrero de 1924, 1. Alberto Bremauntz dice al respecto: "al anochecer del jueves 24, cuando aún estaban entrando a la plaza contingentes de tropas estradistas, tuve el deseo de salir a contemplar las condiciones en que había quedado la ciudad, como asimismo a buscar e informarme de mis compańeros y amigos cuyo fin ignoraba, pero al atravesar la Plaza Principal, frente al Casino, me encontré cinco soldados, que al verme catrín y usando un bastón me detuvieron apuntándome uno de ellos con un rifle y diciéndome que inmediatamente le entregase un reloj pulsera que yo traía; ante semejante petición, hecha con tanta cortesía, me quité el reloj y se lo aventé de retirado. Me dejaron solo, y el que me apuntaba se despidió de mí diciéndome: ‘Ricos condenados, todavía venimos a luchar por ellos y no quieren ayudarnos!' Alberto Bremauntz, Setenta años..., p. 92. Un testimonio más afirma lo siguiente: "Ya que estuvieron los rebeldes adentro, dieron libertad para que hubiera saqueos en diversos comercios del centro y en algunas iglesias. También se supo de atropellos y violaciones a jovencitas [...] a mi padre se le ocurrió asomarse al centro y cuál no sería su sorpresa al 
En la tarde del día 24, cuando todavía se escuchaban los últimos tiros, la soldadesca triunfante, y aun gente del pueblo, se lanzó a saquear algunas tiendas comerciales de primer orden, rompiendo sus puertas y aparadores, entre ellas "El Sombrero Colorado", "La Michoacana", "La Ciudad de París" y algunas tiendas más de ropa, sombrererías y zapaterías fueron saqueadas, al grado de dejarlas completamente vacías. ${ }^{46}$

Ya por la noche y en algunos barrios alejados de la ciudad también fueron saqueadas algunas tiendas de abarrotes de segundo orden. El general Alfredo C. García, que fue en 1921 jefe de operaciones militares en Michoacán, puso algunos avisos ordenando se devolvieran los objetos robados pero no se hizo caso. ${ }^{47}$

Para ir dándole orden y organizar la nueva situación, el 30 de enero de 1924, Manuel M. Diéguez, general de división en jefe de la división de occidente en uso de las facultades que le había investido el "Jefe Supremo de la Revolución”, Adolfo de la Huerta, nombró gobernador provisional del estado de Michoacán al ingeniero Ponciano Pulido. ${ }^{48}$

Al general José Rentería Luviano se le nombró jefe de las Operaciones Militares en el estado y al general Braulio Ramírez, jefe de la Guarnición de la Plaza de Morelia. ${ }^{49}$ Como presidente del ayuntamiento provisional al señor Alberto Izquierdo y regidores José Gutiérrez, Cristóbal Ruiz Gaytán, Pánfilo Téllez, Rafael Elizarrarás, José Reyes Navarro y Martiniano Arredondo. ${ }^{50}$ De los empleados federales comisionados en Morelia, el juez de distrito Ezequiel Parra pasó desapercibido. El jefe de telégrafos Francisco Cepeda sirvió a los rebeldes, hasta después de la batalla de Palo Verde en que derrotados los

ver que los soldados que tomaron la ciudad estaban forzando cerraduras para continuar el saqueo, después en el 'Jardín Melchor Ocampo' le tocó ver a los muertos amontonados como si fueran sardinas, unos con los pies para un lado tocando las cabezas de otros". Carmen Villaseñor, "Mis recuerdos de la rebelión de 1924", en Mensaje, órgano de la sección michoacana del Sindicato Nacional de Maestros Pensionados y Jubilados por el Estado, año III, núm. 13, Morelia, abril de 1991.

${ }^{46}$ Excélsior, México, D. F., 24 de febrero de 1924, 7.

${ }^{47}$ Ibidem.

${ }^{48}$ Archivo Histórico Municipal de Morelia (en adelante AHMM), fondo Siglo xx, caja 306, año de 1924, exp. 4.

${ }^{49}$ AHMM, fondo Siglo xx, caja 304, año de 1924, exp. 49.

${ }^{50}$ Luis Monroy Durán, op. cit., p. 325-326. 
delahuertistas se fue a presentar con Obregón. El administrador de correos José Magańa se mantuvo leal y salvó los fondos de su oficina haciendo anticipos a los empleados. El administrador del timbre Félix Ramírez Magañas se pasó con los rebeldes y les sirvió como delator. Al jefe de hacienda Tomás Martínez Rubio se le obligó a entregar su oficina a Benito Luviano pariente del general Rentería Luviano. ${ }^{51}$

Incluso, las autoridades de la Universidad Michoacana, el rector que en ese entonces era el doctor Salvador González Herrejón y su secretario Manuel Martínez Báez, el presidente del Consejo Superior de Salubridad, Jesús Díaz Barriga, y el regente del Colegio de San Nicolás, Francisco Romero, fueron a ponerse a las órdenes del general Enrique Estrada en su carácter de funcionarios. ${ }^{52}$

En cuanto a los dineros, cerca de 300 mil pesos se produjeron del saqueo y las imposiciones en Morelia. 14 mil de las cajas de la Tesorería General del Estado, tres mil de la Tesorería Municipal, trescientos pesos que el arzobispo de Michoacán, Leopoldo Ruiz y Flores, le envió espontáneamente a Estrada. ${ }^{53}$ Lo demás se obtuvo de préstamos forzosos a las familias adineradas de la ciudad. ${ }^{54}$ Lo anterior a cambio de 500 bajas, entre muertos y heridos, la pérdida de jefes de gran importancia como el general Rafael Buelna, el consumo de medio millón de cartuchos, sin que hubieran encontrado almacenadas en la plaza las municiones que imaginaron, ni el fácil triunfo que se figuraban.

\section{Conclusiones}

El desarrollo de la lucha militar de los rebeldes delahuertistas michoacanos se llevó a cabo bajo la influencia del avance militar de la colum-

${ }^{51}$ Ibidem, pp. 326 y 327.

${ }^{52}$ Se dice que por tal motivo al regreso del gobernador Sidronio Sánchez Pineda, éste sustituyó al doctor González Herrejón como rector de la Universidad Michoacana. Periódico El Cuarto Poder, México, D. F., núm. 10, 12 de abril de 1925, 3.

${ }^{53}$ Luis Monroy Durán, op. cit., p. 324.

${ }^{54}$ Alfonso Taracena, La verdadera Revolución Mexicana, décima etapa, México, Ed. Jus, 1962, 39. El 11 de febrero de 1924, el gobernador provisional Ponciano Pulido publicó un decreto en el que se exigió un préstamo a todos los causantes afectados por el impuesto de patente en el municipio de Morelia correspondiente al anticipo de una mensualidad en un plazo de 18 horas y quien no cumpliera se le multaría con $25 \%$ más. Анмм, fondo Siglo xx, caja 306, ańo de 1924, exp. 4. 
na de Occidente dirigida por el general Enrique Estrada. El grueso de los contingentes rebeldes michoacanos se aglutinó con las fuerzas estradistas para sitiar Morelia. Los demás grupos dispersos, y principalmente el que comandaba Salvador Herrejón, se mantuvieron operando en forma de guerrillas en la zona de Zitácuaro y su acción militar más importante consistió en la ocupación de esa cabecera municipal el 22 de enero de 1924, en los momentos en que se desarrollaban las acciones en Morelia. Unos días más tarde la tuvieron que desocupar al avistar el avance de fuerzas federales para recuperarla.

El sitio y ocupación de Morelia del 22 al 24 de enero puede considerarse como el hecho de armas más relevante de la asonada militar delahuertista en el estado, tanto por el número de efectivos que se enfrentaron, como por el número de bajas y la importancia política que tenía la toma de la capital del estado. Históricamente, también debe resaltarse que fue la primera vez que la conservadora ciudad de Morelia sufrió los efectos de los combates revolucionarios, pues durante las luchas armadas pasadas en pro del maderismo y contra el huertismo nunca había sido asaltada.

Esta victoria militar de los rebeldes fue muy costosa estratégicamente hablando, pues, implicó grandes bajas, entre ellas, la caída del general Rafael Buelna; gran consumo de municiones; y una pérdida de tiempo en el avance que se tenía planeado hacia la capital del país. Lo anterior, gracias a la férrea defensa de la ciudad que hicieron las fuerzas gobiernistas al mando del general Manuel N. López con la colaboración de fuerzas estatales. Este triunfo, que a la postre resultó pírrico, comenzó el declive de la ofensiva rebelde y fue el prolegómeno de sus derrotas definitivas tanto en Ocotlán como en Palo Verde, luego de las cuales sobrevino la desbandada generalizada.

El restablecimiento del control gubernamental en Michoacán inició desde el día 19 de febrero cuando a las doce del día entraron a Morelia las tropas de los generales José Gonzalo Escobar y Jesús M. Aguirre, éste al frente de sus indios mayos. Las campanas de la Catedral fueron echadas a vuelo y la población animada presenció la entrada triunfal desde las calles, balcones y azoteas de sus casas. ${ }^{55}$

${ }^{55}$ Excélsior, segunda sección, México, D. F., 22 de febrero de 1924, 1. 
También fue ocupada a las once de la noche la ciudad de Uruapan, donde los rebeldes abandonaron sus trenes al huir de Pátzcuaro, y de los cuales se apoderaron los coroneles M. Ayala y M. Ortega y el general Pablo Rodríguez, destacados por el general Escobar para controlar las vías férreas. ${ }^{56}$

El 21 de febrero, las principales poblaciones habían sido controladas por las fuerzas del gobierno reanudándose las comunicaciones y servicios públicos con excepción de los municipios de Ario, Tacámbaro, Huetamo, Tuzantla, Arteaga y Coalcomán a donde se dirigieron varios contingentes militares para perseguir a los rebeldes. ${ }^{57}$ Con la llegada de las fuerzas del gobierno a Morelia, el gobernador Sidronio Sánchez Pineda se reinstaló al mando del gobierno del estado el 26 de febrero y se reanudaron los servicios públicos dependientes de la administración estatal..$^{58}$ El Supremo Tribunal de Justicia del Estado reinició labores el 23 de febrero mientras que el Juez de Distrito hasta el 26 del mismo mes. Por su parte el Congreso del Estado, que desde el día 19 de enero había entrado en receso, tuvo su primera sesión el 29 de febrero sin la asistencia de los diputados mugiquistas Luis Mora Tovar, Emilio Moreno, Jesús Pérez Vela, Alberto Coria y Francisco Figueroa Peñaloza. ${ }^{59}$

\section{Anexos}

56 "Sólo queda en Michoacán el liviano de Rentería Luviano pero no tiene ninguna importancia” dijo en su informe el general Gonzalo Escobar al presidente Obregón. El Universal, México, D. F., 21 de febrero de 1924, 1 y 8.

${ }^{57}$ Telegrama del general Vicente González al general Plutarco Elías Calles, 22 de febrero de 1924, FAPECYFT, APEC, Vicente González, exp. 35, num. de inv. 2487, leg. 1. Ario fue recuperado el 25 de febrero cuando el rebelde Constantino Rivera se rindió ante las fuerzas del general Rodríguez

${ }^{58}$ Desde el 21 de febrero al no poderse reunir la Legislatura Local, Silvestre Guerrero, quien llegó con las tropas del general Juan José Ríos, asumió el gobierno provisionalmente como encargado del ejecutivo y a la espera de que arribara el gobernador Sidronio Sánchez Pineda. Éste llegó el 26 de febrero como a las cinco y media, procedente de la ciudad de México por ferrocarril. Para recibirlo se pusieron arreglos florales desde la estación del tren hasta palacio de gobierno. Excélsior, segunda sección, México, D. F., 22 de febrero de 1924, 1, El Universal, México, D. F., 22 de febrero de 1924, 1, АHмM, fondo Siglo xx, caja 304, año de 1924, exp. 49.

${ }^{59}$ Periódico Oficial del Estado de Michoacán, tomo xurv, núm. 48, Morelia, Mich., 23 de marzo de $1924,3$. 


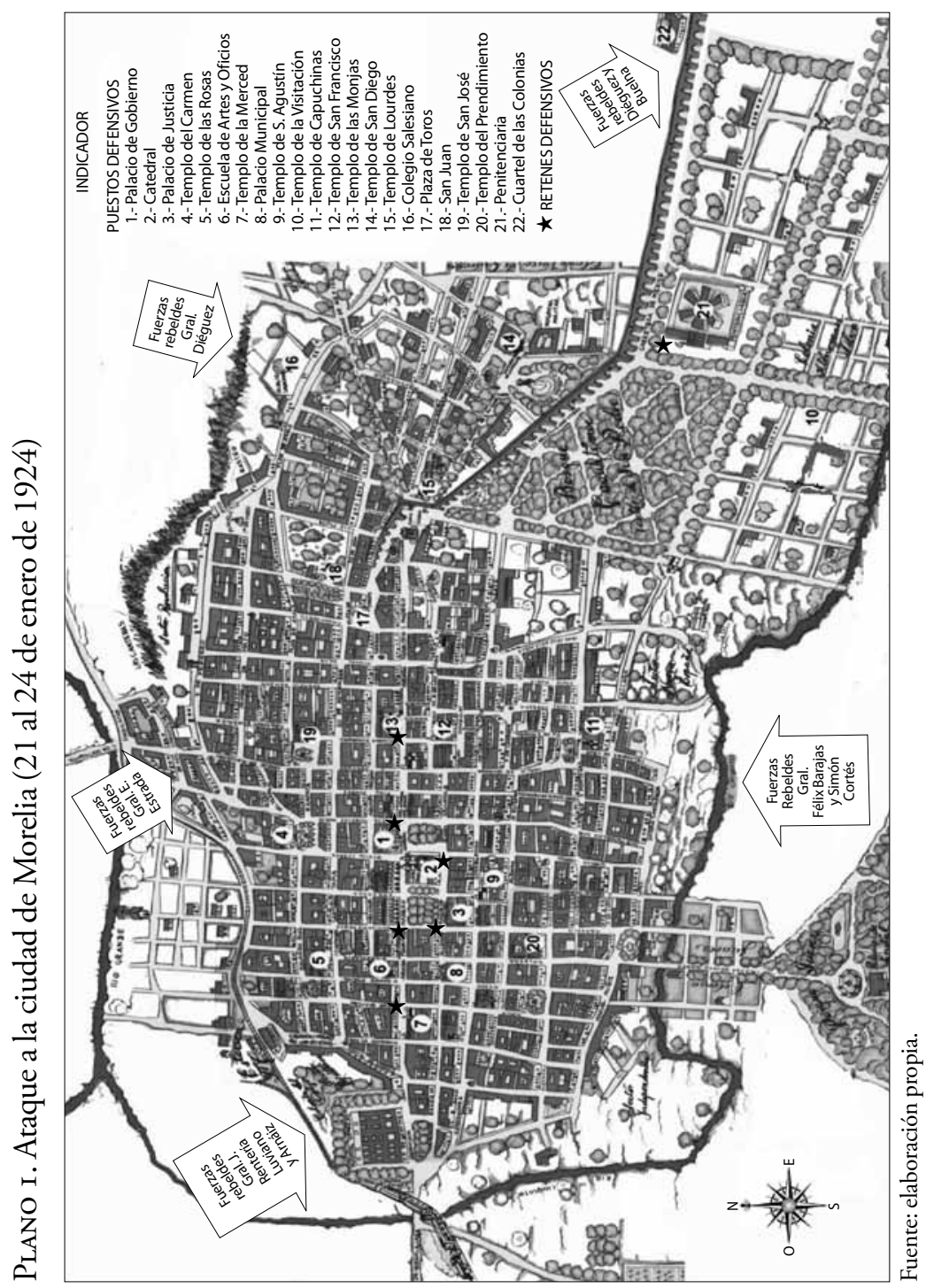




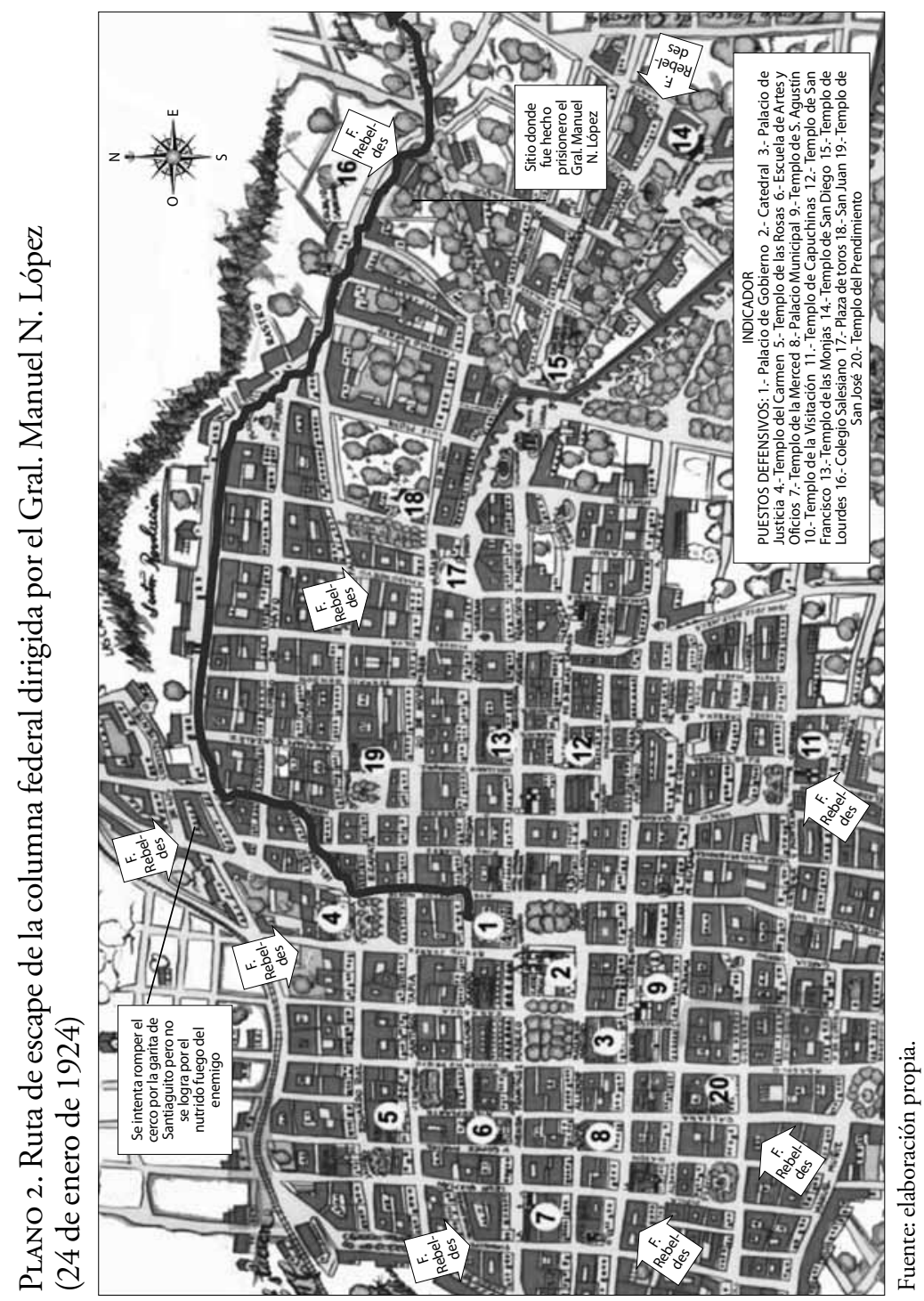




\section{Fuentes UTILIZADAS}

\section{Bibliográficas}

AmaYa, Juan Gualberto, Los gobiernos de Obregón, Calles y regímenes "peleles" derivados del callismo, México, s.i., 1947.

Bremauntz, Alberto, Setenta años de mi vida. Memorias y anécdotas, México, Ediciones Jurídico Sociales, 1968.

CAPETILlo, Alonso, La rebelión sin cabeza: (génesis y desarrollo del movimiento delahuertista), México, Imprenta Botas, 1925.

Castro, Pedro Fernando, Adolfo de la Huerta, la integridad como arma de la revolución, México, Siglo XXI, Universidad Autónoma Metropolitana-Iztapalapa, 1998.

López Victoria, José Manuel, Biografía de Alberto Oviedo Mota, Morelia, uMSNH, 1983.

Llerenas, Fidelina G. y Jaime TAmayo, El levantamiento delahuertista. Cuatro rebeliones y cuatro jefes militares, Zapopan, Universidad de Guadalajara, 1995.

Martínez González, Ma. Guadalupe y María de Jesús Salas DuRÁN, Los presidentes municipales de Huetamo: un siglo de vida politica y administración municipal 1910-2010, México, H. Ayuntamiento Constitucional de Huetamo 2008-2011, Archivo Histórico Municipal de Huetamo "Gral. Jesús Millán Nava”, 2012.

Medina Domínguez, Nazario, La última batalla, Morelia, Editorial Erandi, 1968.

Memorias de Simón Cortés Vieyra (1880-1963), Introducción y notas de Álvaro Ochoa Serrano, Morelia, Gobierno del Estado de Michoacán, 2007.

Millán Nava, Jesús, La Revolución Maderista en el Estado de Guerrero y la Revolución Constitucionalista en Michoacán, México, edición del autor, 1968.

Monroy Durán, Luis, El último caudillo: apuntes para la historia de México, acerca del movimiento armado de 1923, en contra del gobierno constituido, México, José S. Rodríguez Editor, 1924.

Oikión Solano, Verónica, Los hombres del poder en Michoacán, 
1924-1962, Zamora, El Colegio de Michoacán, Universidad Michoacana de San Nicolás de Hidalgo-Instituto de Investigaciones Históricas, 2004.

Pineda Guerrero, Efraín, Crónica de los años muertos, Morelia, Edición del autor, 2007.

Plasencia de la Parra, Enrique, Personajes y escenarios de la rebelión delahuertista, 1923-1924, México, Instituto de Investigaciones Históricas, UNAM, 1998.

Sánchez Rodríguez, Martín, Grupos de poder y centralización política en México. El caso Michoacán, 1920-1924, México, INEHRM, 1994.

Tirado Castro, Sergio, Casas y familias de Morelia remembranzas de la cantera, México, H. Ayuntamiento de Morelia, Consejo de la Ciudad de Morelia, Secretaría de Cultura, Gobierno del Estado de Michoacán, Ediciones Papiro Omega, 2010.

VAladés, José C., Las Caballerías de la Revolución, México, Ediciones Leega-Júcar, 1984.

Villaseñor, Carmen, "Mis recuerdos de la rebelión de 1924”, en Mensaje, órgano de la sección michoacana del Sindicato Nacional de Maestros Pensionados y Jubilados por el Estado, núm. 13, año III, Morelia, abril de 1991.

\section{Hemerográficas}

Excélsior, México, D. F., 9 y 24 de febrero de 1924.

El Universal, México, D. F., 24, 29 de enero de 1924.

El Cuarto Poder, núm. 10, México, D. F., 12 de abril de 1925.

Archivos consultados

Archivo Histórico de la Secretaría de la Defensa Nacional (AHSDN), fondo Cancelados.

Expediente del general Luis de la Sierra, núm. D/III/3-1968.

Expediente del general Nazario Medina Domínguez, núm. x/III/1323.

Expediente del coronel Júpiter Ramírez, núm. R/23-II-78. 
Expediente del general Manuel N. López, núm. XI/III/3-2815

Expediente del general Cecilio García, sin núm.

Archivo Histórico de la Universidad Nacional Autónoma de México (ahunam), fondo Amado Aguirre, caja III, exp. 9, fs. 48-50.

Archivo General de la Nación (AGN), fondo Presidentes ObregónCalles, exp. 101-R-2-B-1.

Archivo Histórico Municipal de Morelia (AHMM), fondo Siglo XX, caja 304 y 306, año de 1924.

FeCHA DE RECEPCIÓN DEL ARTículo: 19 de noviembre de 2013

FECHA DE APROBACIÓN: 10 de febrero de 2014

FECHA DE RECEPCIÓN DE LA VERSIÓN FINAL: 17 de febrero de 2014 